\title{
Clinical impact of omalizumab in refractory chronic urticaria: One centre experience
}

\author{
DIANA DELEANU ${ }^{1-3}$, IRENA NEDELEA $^{1,3}$, CARINA PETRICAU $^{1,2}$, \\ POLIANA LERU ${ }^{4,5}$, DINU DUMITRASCU ${ }^{6}$ and ADRIANA MUNTEAN ${ }^{1,3}$
}

\author{
${ }^{1}$ Allergy Department and ${ }^{2}$ Internal Medicine Department, Professor Doctor Octavian Fodor Regional Institute of \\ Gastroenterology and Hepatology, 400162 Cluj-Napoca; ${ }^{3}$ Allergology and Immunology Discipline, \\ Iuliu Hatieganu University of Medicine and Pharmacy, 400012 Cluj-Napoca; ${ }^{4}$ Carol Davila University \\ of Medicine and Pharmacy, 050474 Bucharest; ${ }^{5}$ Clinic of Internal Medicine-Allergology Department, \\ Colentina Clinical Hospital, 020125 Bucharest; ${ }^{6}$ Anatomy Discipline, Iuliu Hatieganu University \\ of Medicine and Pharmacy, 400012 Cluj-Napoca, Romania
}

Received September 6, 2019; Accepted October 7, 2019

DOI: $10.3892 / \mathrm{etm} .2019 .8126$

\begin{abstract}
Chronic spontaneous urticaria is a debilitating disorder, which has a major impact on the quality of life of affected individuals, and is a substantial global burden. Refractory, difficult to treat cases pose a difficult challenge to patients and clinicians alike. Advances in the field of immunotherapy have led to novel and effective therapeutic strategies. Omalizumab, an immunomodulatory anti-IgE monoclonal antibody, inaugurated a new era in the treatment of refractory chronic urticaria. Several multicenter clinical trials have proven omalizumab to be a safe and effective option for the treatment of refractory symptoms of chronic spontaneous urticaria, while some small studies have shown its efficacy in chronic inductible urticaria as well. In this study, we bring forth updates in chronic urticaria approach, with a focus on our experience with anti-IgE therapy in different forms of chronic urticaria treated at the Allergy Department of the Professor Doctor Octavian Fodor Regional Institute of Gastroenterology and Hepatology (Cluj-Napoca, Romania).
\end{abstract}

\section{Introduction}

Urticaria encompasses a group of disorders characterized by wheals, angioedema, or both. It is one of the most frequent skin disorders, 'characterized by pruritic wheal and flare-type skin reactions with or without angioedema that usually persist for $<24$ h' (1). Urticaria is classified as acute or chronic based on

Correspondence to: Dr Irena Nedelea, Allergology and Immunology Discipline, Iuliu Hatieganu University of Medicine and Pharmacy, 8 Babes Street, 400012 Cluj-Napoca, Romania

E-mail: irennedelea@gmail.com

Key words: chronic spontaneous urticaria, inductible urticaria, refractory urticaria, omalizumab, anti-IgE therapy the duration of the disease. Acute spontaneous urticaria is characterized by the occurrence of spontaneous pruritic wheals, angioedema or both for less than six weeks. In contrast, chronic urticaria (CU) encompasses a group of disorders characterized by the recurrence of pruritic wheals, occurring on most days during the week, for longer than six weeks, and accompanied by angioedema in $>50 \%$ of the cases. In some patients, angioedema is the only clinical feature of the disease (2).

Recent advances in this field have led to a better understanding of incriminated mechanisms and to novel and effective therapeutic strategies. The 2018 EAACI/GA ${ }^{2}$ LEN/ $\mathrm{EDF} / \mathrm{WAO}$ guideline for the definition, classification, diagnosis and management of urticaria recommends classification of urticaria as spontaneous, non-dependent of a specific elicitating factor, or inducible, when a specific trigger elicits the reaction. According to statistical studies, the lifetime prevalence of acute spontaneous urticaria is almost $20 \%$ (2). The estimated point prevalence of CSU (percentage of population affected at any time) is $0.5-1 \%$ (1), while the incidence of the various subtypes of CU remains to be defined. The reported prevalence of CSU in adult population varies between $0.5 \%$ and $5 \%(3-5)$. There is scarce data on the prevalence of CSU in paediatric population. However, it is considered that CSU is more prevalent in adults. In the authors' experience, an increasing number of medical visits are related to CSU.

CSU is frequently a debilitating disorder, which has a major impact on the quality of life, due to the persistent pruritus, regular recurrence of symptoms, unascertained etiology, sleep deprivation and psychiatric co-morbidity being a frequent finding in affected individuals. The global burden of disease is substantial, considering the health care costs, as well as reduced functional impairment at work and in private life $(6,7)$. Refractory, difficult to treat cases pose a demanding challenge to patients and clinicians alike.

Advances in the field of immunotherapy have led to novel and effective therapeutic strategies. The current CSU treatment algorithm follows a step-wise approach, starting with standard doses of second-generation non-sedative $\mathrm{H} 1$ 
antihistamines as the first-line treatment. Up-dosing of up to a 4-fold increase of $\mathrm{H} 1$ antihistamines in cases non-responsive after 2-4 weeks of first line treatment, or earlier, if symptoms are intolerable is the second line of treatment. Omalizumab, a humanized anti-IgE monoclonal antibody, represents the third-line treatment, in cases with CSU refractory to treatment with maximum-dose of 2 nd generation antihistamines for 2-4 weeks, or earlier, if symptoms are severe. Corticosteroids are reserved for short-term intervention in severe cases, while add-on drugs such as cyclosporine are of limited use due to the risk of adverse reactions (8). Several multicenter clinical trials have proven omalizumab to be a safe and effective option for the treatment of refractory symptoms of CSU (8-14), while some small studies have shown its efficacy in chronic inducible urticaria as well $(15,16)$, including cholinergic urticaria (17), cold urticaria $(18,19)$, solar urticaria $(20)$, heat urticaria $(21)$, symptomatic dermographism $(22,23)$, and delayed pressure urticaria (24).

\section{Patients and methods}

Patient population and study design. This study is a retrospective case series of patients $(n=37)$ with refractory CSU and/or CINDU, diagnosed and treated with omalizumab in the Allergy Department of the Professor Doctor Octavian Fodor Regional Institute of Gastroenterology and Hepatology, (Cluj-Napoca, Romania), between April 2018 and March 2019. The database comprised of information retrieved from patients' observation sheets from the archive of the Allergy Department. Omalizumab (Xolair ${ }^{\circledR}$ ) was used in patients with CSU and/or inducible urticarias and who had persistent or recurrent symptoms for at least 4 weeks after second-line treatment (4-fold the licensed dose), as per EAACI/GA ${ }^{2} \mathrm{LEN} /$ EDF/UNEV consensus recommendations. Signed informed consent was obtained from all the patients before the initiation of therapy. Omalizumab was given subcutaneously in dose of $300 \mathrm{mg}$ every month per patient for 6 months. Patients were followed up for 6 months after the first 6 months of treatment. Age, sex, prior and concomitant drug therapy, co-morbidities, presence of angioedema, disease duration from onset of clinical manifestations to anti-IgE therapy was recorded. None of the patients included in the study received cyclosporine prior to omalizumab treatment. The study was approved by the Ethics Committee of the Professor Doctor Octavian Fodor Regional Institute of Gastroenterology and Hepatology.

Assesement of CSU activity and definitions of response. Patients were assessed for disease activity, impact and level of control with the weekly urticaria activity score (UAS7) (25), and the urticaria control test (UCT) (26).

UAS7 was used for the assessment of disease severity prior to anti-IgE-therapy, and for evaluation of treatment response. UAS7 values correspond to five score bands (0, 1-6, $7-15,16-27,28-42)$, reflecting urticaria-free to severe disease activity. According to the post-treatment values of UAS7, response to treatment with omalizumab was stratified into: complete response: UAS7 $=0$, and well-controlled disease: UAS7 $\leq 6(1,27)$. In terms of the time elapsed until clinical improvement, response was classified as early when noted in the first month, late when it occurred after 3 months of therapy,
Table I. Patient sample characteristics.

\begin{tabular}{lcc}
\hline Characteristics & No. & Percentage \\
\hline Sex & & \\
Female & 30 & $81.08 \%$ \\
Male & 7 & $18.91 \%$ \\
Mean age & 44.89 & \\
Female:male & $45.90: 40.57$ & \\
Disease duration (months) & 17.75 & \\
Diagnosis & & \\
CSU & 29 & $78.37 \%$ \\
CSU plus symptomatic & 4 & $10.81 \%$ \\
dermographism & & \\
CSU plus aquagenic urticaria & 1 & $2.70 \%$ \\
CSU plus cold-induced urticaria & 3 & $8.10 \%$ \\
Concurrent angioedema & 13 & $35.3 \%$ \\
Co-morbidities & & \\
Polycythemia vera & 1 & $2.70 \%$ \\
Hashimoto's thyroiditis & 3 & $8.10 \%$ \\
Allergic rhinitis & 1 & $2.70 \%$ \\
Asthma & 1 & $2.70 \%$ \\
\hline
\end{tabular}

and intermediate when noted during the second and the third month of treatment (28).

Post-treatment values of UCT were also used for the evaluation of treatment response: patients who did not require antihistamines for the 6 months of follow-up (UCT score $>12$ ) were included in the category of disease remission, those who were asymptomatic on first-line treatment with low-dose antihistamines (UCT score $>12$ ) were considered as having a complete response, patients who required continued treatment with omalizumab, concomitantly with antihistaminic drugs (UCT score $>12$ ) were classified as having a partial response, while those who continued to be symptomatic despite treatment with omalizumab along with antihistamines (UCT <12) were included in the non-responder category.

\section{Results}

Demographics. Most patients $(n=30,81.08 \%)$ were females aged between 18 and 68 years, with mean age being 44.89 years in the entire study lot, 45.90 in the female group and 40.57 in the male group, respectively. Geographic locations of participants were represented as follows: 6 patients $(16.21 \%$ of total) were from a rural area while 31 patients $(83.79 \%$ of total) from urban area (Table I).

Disease characteristics. The patients had a long personal history of CSU and/or CINDU. Duration of disease ranged from 12 to 36 months with the average of 17.75 months (approximately one and a half years). CSU was associated with CINDU in $21.62 \%$ of cases, namely with symptomatic dermographism in 4 patients $(10.81 \%)$, cold-induced urticaria in 3 patients $(8.10 \%)$, and aquagenic urticaria in one patient $(2.70 \%)$. The latter had concurrent haematological disease 
(polycythemia vera). Three patients $(10.81 \%)$ had cold-induced urticaria. Angioedema was an intermittent feature of the disease in 13 of patients, accounting for $35.13 \%$ of the studied group. Hashimoto's thyroiditis was concomitant with CSU in $8.10 \%(n=3)$, one patient had concurrent asthma, and in one of the patients, CSU was associated with allergic rhinitis (Table I).

Treatment. All patients were unresponsive to treatment with maximum-dose of $\mathrm{H} 1$ antihistamines and some of them required short courses of glucocorticoids by the time omalizumab treatment was considered. Omalizumab was administered at the dose of $300 \mathrm{mg}$ per month for 6 months in all patients. All patients were advised to continue anti-H1 antihistamine treatment.

Treatment response. All the patients had severe disease activity with pre-omalizumab UAS7 scores ranging from 28 to 42 (mean: 39). All of the patients responded to treatment with omalizumab. Post-treatment UAS7 showed complete response in $31 / 37$ patients $(84 \%)$ and well-controlled disease in the remaining $6 / 37$ patients (16\%), after administration of one to six doses of omalizumab (mean: 2.10). In terms of time of response, most patients, 20/37 (54\%) responded 'early', within the first month, 10/37 (27\%) responded during the second and the third month of treatment ('intermediate'), while 'late' response, which occurred after 3 months of therapy was noted in the remaining $7 / 37$ patients (19\%). The late response category included the three patients with concurrent autoimmune phenomena (Hashimoto's thyroiditis), the patient with polycythemia vera associated with aquagenic urticaria, and three patients with CSU. All of the patients with CSU and symptomatic dermographism $(n=4)$, as well as patients with CSU and cold-induced urticaria $(n=3)$ responded effectively to omalizumab, being in the 'early' complete responder category. Four out of the seven patients with 'late' response had concurrent angioedema. No adverse reactions were recorded during omalizumab administration.

According to the post-treatment values of UCT, $8 / 37$ patients (23\%) underwent remission and remained asymptomatic despite discontinuation of antihistamine treatment, 19/37 patients (51\%) had a complete response to treatment with disease being controlled with first line treatment (low doses of $\mathrm{H} 1$ antihistamines), while $3 / 37$ patients $(8.10 \%$ ) had a partial response, and required both omalizumab and low-dose antihistamines to remain asymptomatic. The latter category included the patient with aquagenic urticaria, and two patients with CSU. Treatment with omalizumab was reinitiated three months after discontinuation in 7 of the patients, due to reoccurrence of symptoms which were refractory to the second-line treatment. The present study did not include any non-responders to omalizumab therapy.

\section{Discussion}

CSU is more frequently seen in women than in men, with a ratio of 2:1, which was also observed in our group (most patients were females). Moreover, a higher rate of severe CSU is seen in female patients, which may explain the significant percentage of women receiving omalizumab therapy in our study.

Omalizumab has been shown to be very effective and safe in the treatment of CSU, as well as in CINDU, such as cholinergic urticaria, cold urticaria, solar urticaria, heat urticaria, symptomatic dermographism, and delayed pressure urticaria. In the authors' experience, anti-IgE therapy with omalizumab has the potential to bring spectacular clinical benefits in refractory CSU, as well as in cases of cold-induced urticaria and symptomatic dermographism. One patient with aquagenic urticaria refractory to maximum-dose antihistamine treatment was enrolled in our study. The patient responded well to the treatment. However, concomitant low-dose of antihistamine was required to control the disease, and severe poorly controlled symptoms reoccurred after the end of the 6 months of treatment, which required re-administration of omalizumab. In this case, omalizumab was the only agent that controlled the disease. Published data also plead for successful treatment with omalizumab of aquagenic urticaria (29).

Almost one quarter of the cases underwent remission, while more than half of them had a complete response to treatment. None of the patients required oral corticosteroids to control the disease while being treated with omalizumab. Only a small percentage of the patients required both omalizumab and antihistamine therapy. Monotherapy with omalizumab proved effective in an overwhelming majority (92\%) of the cases. Recurrent symptoms responded favourably to the reinition of anti-IgE therapy in $19 \%$ of the cases. Best clinical response was noted within the first month of treatment, as noted in more than half of the cases, while only $19 \%$ of the patients had a 'late' response after 3 to 6 months of treatment. This finding is consistent with published data $(11-13,30)$ on CSU being well-controlled after a single dose of omalizumab.

Chronic spontaneous urticaria greatly impacts the quality of life of affected individuals. Omalizumab was confirmed to be a safe and effective therapeutic approach for refractory cases of chronic spontaneous urticaria. In our experience, anti-IgE therapy brought significant clinical benefits and ensured a normal quality of life in patients with refractory chronic spontaneous urticaria, cold urticaria, and aquagenic urticaria.

\section{Acknowledgements}

We would like to acknowledge Doctor Mlesnite Mihai Adrian, the Manager of the Professor Doctor Octavian Fodor Regional Institute of Gastroenterology and Hepatology (Cluj-Napoca, Romania), for ensuring treatment is available for the patients included in this study.

\section{Funding}

No funding was received.

\section{Availability of data and materials}

The datasets used during the present study are available from the corresponding author upon reasonable request.

\section{Authors' contributions}

DDe, IN, CP, PL, DDu and AM participated in the analysis of current published data, as well as in the planning and writing of the manuscript. All authors have read and approved the final version of the manuscript. 


\section{Ethics approval and consent to participate}

The study was approved by the Ethics Committee of the Professor Doctor Octavian Fodor Regional Institute of Gastroenterology and Hepatology (Cluj-Napoca, Romania). Signed informed consent was obtained from all the patients before the initiation of therapy.

\section{Patient consent for publication}

Not applicable.

\section{Competing interests}

The authors declare that they have no competing interests.

\section{References}

1. Maurer M, Weller K, Bindslev-Jensen C, Giménez-Arnau A Bousquet PJ, Bousquet J, Canonica GW, Church MK, Godse KV, Grattan CE, et al: Unmet clinical needs in chronic spontaneous urticaria. A GA ${ }^{2}$ LEN task force report. Allergy 66: 317-330, 2011

2. Zuberbier T, Aberer W, Asero R, Abdul Latiff AH, Baker D, Ballmer-Weber B, Bernstein JA, Bindslev-Jensen C, Brzoza Z, Buense Bedrikow R, et al; Endorsed by the following societies: AAAAI, AAD, AAIITO, ACAAI, AEDV, APAAACI, ASBAI, ASCIA, BAD, BSACI, CDA, CMICA, CSACI, DDG, DDS DGAKI, DSA, DST, EAACI, EIAS, EDF, EMBRN, ESCD, GA²LEN, IAACI, IADVL, JDA, NVvA, MSAI, ÖGDV, PSA, RAACI, SBD, SFD, SGAI, SGDV, SIAAIC, SIDeMaST, SPDV, TSD, UNBB, UNEV and WAO: The EAACI/GA ${ }^{2} \mathrm{LEN} / \mathrm{EDF} /$ WAO guideline for the definition, classification, diagnosis and management of urticaria. Allergy 73: 1393-1414, 2018.

3. Zuberbier T, Balke M, Worm M, Edenharter G and Maurer M: Epidemiology of urticaria: A representative cross-sectional population survey. Clin Exp Dermatol 35: 869-873, 2010.

4. Bernstein JA, Lang DM, Khan DA, Craig T, Dreyfus D, Hsieh F, Sheikh J, Weldon D, Zuraw B, Bernstein DI, et al: The diagnosis and management of acute and chronic urticaria: 2014 update. J Allergy Clin Immunol 133: 1270-1277, 2014.

5. Gaig P, Olona M, Muñoz Lejarazu D, Caballero MT, Domínguez FJ, Echechipia S, García Abujeta JL, Gonzalo MA, Lleonart R, Martínez Cócera C, et al: Epidemiology of urticaria in Spain. J Investig Allergol Clin Immunol 14: 214-220, 2004.

6. Maurer M, Abuzakouk M, Bérard F, Canonica W, Oude Elberink H, Giménez-Arnau A, Grattan C, Hollis K, Knulst A, Lacour JP, et al: The burden of chronic spontaneous urticaria is substantial: Real-world evidence from ASSURE-CSU. Allergy 72: 2005-2016, 2017.

7. Magerl M, Altrichter S, Borzova E, Giménez-Arnau A, Grattan CE, Lawlor F, Mathelier-Fusade P, Meshkova RY, Zuberbier T, Metz M, et al: The definition, diagnostic testing, and management of chronic inducible urticarias - The EAACI/GA(2) $\mathrm{LEN} / \mathrm{EDF} / \mathrm{UNEV}$ consensus recommendations 2016 update and revision. Allergy 71: 780-802, 2016.

8. Maxim E, Aksut C, Tsoi D and Dellavalle R: Global burden of urticaria: Insights from the 2016 Global Burden of Disease Study. J Am Acad Dermatol 79: 567-569, 2018.

9. Saini S, Rosen KE, Hsieh HJ, Wong DA, Conner E, Kaplan A, Spector S and Maurer M: A randomized, placebo-controlled, dose-ranging study of single-dose omalizumab in patients with H1-antihistamine-refractory chronic idiopathic urticaria. J Allergy Clin Immunol 128: 567-573.e1, 2011.

10. Maurer M, Altrichter S, Bieber T, Biedermann T, Bräutigam M, Seyfried S, Brehler R, Grabbe J, Hunzelmann N, Jakob T, et al: Efficacy and safety of omalizumab in patients with chronic urticaria who exhibit IgE against thyroperoxidase. J Allergy Clin Immunol 128: 202-209.e5, 2011.

11. Saini SS, Bindslev-Jensen C, Maurer M, Grob JJ, Bülbül Baskan E, Bradley MS, Canvin J, Rahmaoui A, Georgiou P, Alpan O, et al: Efficacy and safety of omalizumab in patients with chronic idiopathic/spontaneous urticaria who remain symptomatic on $\mathrm{H} 1$ antihistamines: A randomized, placebo-controlled study. J Invest Dermatol 135: 67-75, 2015.
12. Maurer M, Rosén K, Hsieh HJ, Saini S, Grattan C, Gimenéz-Arnau A, Agarwal S, Doyle R, Canvin J, Kaplan A, et al: Omalizumab for the treatment of chronic idiopathic or spontaneous urticaria. N Engl J Med 368: 924-935, 2013.

13. Kaplan A, Ledford D, Ashby M, Canvin J, Zazzali JL, Conner E, Veith J, Kamath N, Staubach P, Jakob T, et al: Omalizumab in patients with symptomatic chronic idiopathic/spontaneous urticaria despite standard combination therapy. J Allergy Clin Immunol 132: 101-109, 2013.

14. Zhao ZT, Ji CM, Yu WJ, Meng L, Hawro T, Wei JF and Maurer M: Omalizumab for the treatment of chronic spontaneous urticaria: A meta-analysis of randomized clinical trials. J Allergy Clin Immunol 137: 1742-1750.e4, 2016.

15. Maurer M, Metz M, Brehler R, Hillen U, Jakob T, Mahler V, Pföhler C, Staubach P, Treudler R, Wedi B, et al: Omalizumab treatment in patients with chronic inducible urticaria: A systematic review of published evidence. J Allergy Clin Immunol 141: 638-649, 2018.

16. Metz M, Altrichter S, Ardelean E, Kessler B, Krause K, Magerl M, Siebenhaar F, Weller K, Zuberbier T and Maurer M: Anti-immunoglobulin E treatment of patients with recalcitrant physical urticaria. Int Arch Allergy Immunol 154: 177-180, 2011.

17. Metz M, Bergmann P, Zuberbier T and Maurer M: Successful treatment of cholinergic urticaria with anti-immunoglobulin $\mathrm{E}$ therapy. Allergy 63: 247-249, 2008.

18. Metz M, Schütz A, Weller K, Gorczyza M, Zimmer S, Staubach P, Merk HF and Maurer M: Omalizumab is effective in cold urticaria-results of a randomized placebo-controlled trial. J Allergy Clin Immunol 140: 864-867.e5, 2017

19. Boyce JA: Successful treatment of cold-induced urticaria/ anaphylaxis with anti-IgE. J Allergy Clin Immunol 117: 1415-1418, 2006

20. Güzelbey O, Ardelean E, Magerl M, Zuberbier T, Maurer M and Metz M: Successful treatment of solar urticaria with antiimmunoglobulin E therapy. Allergy 63: 1563-1565, 2008.

21. Bullerkotte U, Wieczorek D, Kapp A and Wedi B: Effective treatment of refractory severe heat urticaria with omalizumab. Allergy 65: 931-932, 2010.

22. Krause K, Ardelean E, Kessler B, Magerl M, Metz M, Siebenhaar F, Weller K, Worm M, Zuberbier T and Maurer M: Antihistamine-resistant urticaria factitia successfully treated with anti-immunoglobulin E therapy. Allergy 65: 1494-1495, 2010.

23. Maurer M, Schütz A, Weller K, Schoepke N, Peveling-Oberhag A, Staubach P, Müller S, Jakob T and Metz M: Omalizumab is effective in symptomatic dermographism - results of a randomized placebo-controlled trial. J Allergy Clin Immunol 140: 870-873.e5, 2017.

24. Bindslev-Jensen C and Skov PS: Efficacy of omalizumab in delayed pressure urticaria: A case report. Allergy 65: 138-139, 2010.

25. Zuberbier T, Aberer W, Asero R, Bindslev-Jensen C, Brzoza Z, Canonica GW, Church MK, Ensina LF, Giménez-Arnau A, Godse K, et al; European Academy of Allergy and Clinical Immunology; Global Allergy and Asthma European Network; European Dermatology Forum; World Allergy Organization: The EAACI/GA(2) LEN/EDF/WAO Guideline for the definition, classification, diagnosis, and management of urticaria: The 2013 revision and update. Allergy 69: 868-887, 2014.

26. Weller K, Groffik A, Church MK, Hawro T, Krause K, Metz M, Martus P, Casale TB, Staubach P and Maurer M: Development and validation of the Urticaria Control Test: a patient-reported outcome instrument for assessing urticaria control. J Allergy Clin Immunol 133: 1365-1372.e1-6, 2014.

27. Młynek A, Zalewska-Janowska A, Martus P, Staubach P, Zuberbier T and Maurer M: How to assess disease activity in patients with chronic urticaria? Allergy 63: 777-780, 2008.

28. Syrigos N, Grapsa D, Zande M, Tziotou M and Syrigou E: Treatment response to omalizumab in patients with refractory chronic spontaneous urticaria. Int J Dermatol 57: 417-422, 2018.

29. Rorie A and Gierer S: A case of aquagenic urticaria successfully treated with omalizumab. J Allergy Clin Immunol Pract 4: $547-548,2016$

30. Sussman G, Hébert J, Barron C, Bian J, Caron-Guay RM, Laflamme $\mathrm{S}$ and Stern S: Real-life experiences with omalizumab for the treatment of chronic urticaria. Ann Allergy Asthma Immunol 112: 170-174, 2014. 